\title{
CÂNCER DE MAMA EM CADELAS - ATUALIDADES DO DIAGNÓSTICO E PROGNÓSTICO AO TRATAMENTO CIRÚRGICO
}

\author{
Bruna Luiza Carelli Teixeira Estralioto ${ }^{1}$, Juliano Bortolo De Conti ${ }^{2}$ \\ ${ }^{1}$ Médica Veterinária, Mestranda Produção Sustentável e Saúde Animal da \\ Universidade Estadual de Maringá - UEM Campus Umuarama - \\ bruna.carelli@gmail.com \\ ${ }^{2}$ Médico Veterinário, Professor Doutor do Departamento de Medicina Veterinária da \\ Universidade Estadual de Maringá - UEM Campus Umuarama
}

Recebido em: 06/04/2019 - Aprovado em: 10/06/2019 - Publicado em: 30/06/2019 DOI: 10.18677/EnciBio_2019A33

\begin{abstract}
RESUMO
O câncer de mama é indubitavelmente um dos principais motivos pelos quais tutores levam seus animais à clínica veterinária, decorrente da alta incidência desta afecção. Os animais mais acometidos são fêmeas intactas, de 7 a 12 anos. Normalmente a queixa principal do tutor se deve às nodulações em alguma ou diversas mamas, que podem variar de nódulos com menos de $0,5 \mathrm{~cm}$ de diâmetro, até maiores do que $5 \mathrm{~cm}$. O diagnóstico do câncer é feito através de exames clínicos, citológicos e histopatológicos, e a seleção do tratamento é feita com base nas características individuais da doença no paciente, e envolve o estadiamento da doença com base no número de nódulos, afecção linfonodal e presença de metástases à distância. Neste sentido, exames complementares de imagens são imprescindíveis para a abordagem do quadro. O tratamento cirúrgico é o preconizado, pois, uma vez selecionado corretamente, pode promover a cura para a doença naquele paciente. Os critérios para a seleção da técnica ainda é algo discutido, e leva em consideração as características da doença em cada paciente. Biomarcadores podem ser utilizados como fatores prognósticos e preditivos para auxílio do cirurgião na seleção da técnica a ser empregada, e assim, permitir o melhor tratamento para cada paciente.
\end{abstract}

PALAVRAS-CHAVE: Imuno-histoquímica, neoplasias mamárias, mastectomia.

\section{BREAST CANCER IN BITCHES - ATUALIZATIONS FROM DIAGNOSIS AND PROGNOSIS TO CURGICAL TREATMENT}

\begin{abstract}
Breast cancer is undoubtedly one of the principal reasons for dogs owners bringing the animals to the veterinarian, because of the high incidence of the disease. The most affected animals are intact, aging from 7 to 12 years old. The most complains of the tutors are due to single or several nodulations affecting the mammary tissue, which can vary from nodules with less than $0.5 \mathrm{~cm}$ in diameter, to greater than $5 \mathrm{~cm}$. The diagnosis is made through clinical,
\end{abstract}


cytological and histopathological examinations, and the selection of the treatment is made based on the individual characteristics of the patients disease, and it depends on the cancer staging that is based on the number of nodules, the lymph node affection, and the presence of metastasis in distant sites. In this sense, imaging exams are essential for the selection of the approach. Surgical treatment is recommended because, once properly selected, it can promote a cure for the previous patient. The criteria for the selection of the technique are discussed and considered as characteristics of the disease in each patient. Biomarkers can be used as prognostic and predictive factors to aid the surgery in the selection of the technique to be used, and thus, to allow the best treatment for each patient.

KEYWORDS: Mammary neoplasia, mastectomy, mmunohistochemistry.

\section{INTRODUÇÃO}

A prevalência de aparecimento do câncer em pequenos animais está aumentando consideravelmente por várias razões, entre elas a principal é a maior longevidade observada nestes animais. Nutrição com dietas balanceadas, vacinações mais rigorosas, avançados métodos de diagnóstico e também os protocolos terapêuticos cada vez mais específicos e eficazes, contribuem para a maior longevidade dos cães.

Em razão da elevada incidência dos tumores mamários em fêmeas, principalmente da espécie canina, seu estudo vem crescendo em relação a todos os aspectos deste problema. Tutores exigem cada vez mais que seus animais de estimação tenham atenção semelhante àquela prestada aos doentes humanos. Além disso, as cadelas são consideradas um excelente modelo comparativo ao entendimento da carcinogênese dessa neoplasia em virtude de os aspectos epidemiológicos, clínicos, comportamento biológico e molecular serem semelhantes aos apresentados nas mulheres.

O principal objetivo deste trabalho é revisar a apresentação, diagnóstico, além de reunir as atualizações quanto às técnicas cirúrgicas utilizadas para o tratamento do câncer de mama em cadelas, considerando, inclusive, sua seleção. Além disso, serão observados os principais avanços na determinação de marcadores moleculares do prognóstico destes pacientes, considerando se sua avaliação traz, ou não benefícios para a determinação do prognóstico do câncer em cadelas.

\section{Neoplasias mamárias em cadelas}

O câncer é tratado na atualidade como uma doença crônica, e os avanços dentro da Medicina Veterinária tem trazido longevidade e qualidade de vida para os pacientes oncológicos. A abordagem terapêutica deste paciente é determinante para que o prognóstico do paciente seja o melhor possível, e deve ser feito de maneira individual, porém metódica.

Os tumores de glândula mamária são os tumores mais frequentemente encontrados em cadelas, podendo representar de 50 a $70 \%$ de todas as neoplasias encontradas na espécie canina (DE NARDI et al., 2016). Quando em paralelo com humanos, estudos conduzidos que geram um perfil do câncer de mama na América Latina, acredita-se que aproximadamente 20.000 novos casos sejam diagnosticados por ano, sendo responsáveis pela morte de aproximadamente 52.000 pessoas por ano (PINTO et al., 2019). Neste contexto de América Latina, o Brasil é o terceiro colocado no ranking de aparecimento de novos casos (PINTO et al., 2019). Ainda, em se tratando de câncer de mama em mulheres, 
é importante ressaltar que estudos demonstram a importância do efetivo acesso ao diagnóstico e tratamento desse tipo de doença, demonstrando as discrepâncias nos panoramas de países da América Latina comparado a países mais desenvolvidos (STRASSER-WEIPPL et al., 2015). Assim vê-se, mais uma vez a importância no estudo e desenvolvimento do diagnóstico e tratamento deste câncer, o que eleva cada vez mais o papel do médico veterinário no tratamento dos pacientes animais.

De acordo com De Nardi, et al. (2002), 68,4\% destas neoplasias são malignas e afetam principalmente fêmeas com idades entre 7 e 12 anos. Um estudo de Terzian et al. (2007) demonstrou que o principal tipo histológico envolvido normalmente é o carcinoma em suas diferentes apresentações. De acordo com Cassali et al. (2014), os tumores de mama podem afetar fêmeas caninas intactas e inclusive as castradas. Vale ainda ressaltar, que este tipo de neoplasia não é uma exclusividade dos pacientes femininos, sendo que a incidência em machos é pequena, mas mais comumente está presente nos casos em que o paciente apresenta, associadamente, sertoliomas testiculares, que causam hiperestrogenia.

\section{Apresentação clínica}

De maneira geral, as cadelas com tumores mamários estão clinicamente saudáveis no momento do diagnóstico e os tumores podem ser facilmente identificados por um profissional durante o exame físico de rotina (DE NARDI et al., 2016). E de forma paralela, em humanos, o auto-exame de rotina é uma das ferramentas mais efetivas para a detecção do câncer de mama nos seus estágios mais iniciais (PINTO et al., 2019), o que ressalta mais ainda a importância que os exames de rotina em consultórios veterinários sempre sejam feitos de forma completa.

Os tumores normalmente são nódulos circunscritos, bem delimitados, podendo ser bem pequenos ou de elevado tamanho em região de glândulas mamárias (DE NARDI et al., 2016). Outras formas de apresentação, como por exemplo formas irregulares, ulceradas e com diferentes graus de mobilidade e aderência também podem ser percebidas ao exame físico (DE NARDI et al., 2016). Alguns tumores, principalmente os de crescimento rápido, podem apresentar ulcerações e áreas de necrose, que comumente apresentam inflamação e infecção bacteriana secundária (DE NARDI et al., 2016).

As mamas abdominais caudais e as inguinais são mais frequentemente afetadas, por justamente apresentarem tecido mamário mais desenvolvido, e de Nardi et al. (2016) afirmam que 66\% das neoplasias mamárias encontram-se nessas glândulas. Este mesmo autor, ainda relata que em $70 \%$ dos casos, mais de um tumor está acometendo a mesma glândula, ou glândulas adjacentes, que podem ou não pertencer ao mesmo tipo histológico. Por este motivo, todos os tumores mamários devem ser biopsados, pois normalmente tratam-se de novos tumores primários, sendo que os tumores com pior prognóstico devem servir de parâmetro para avaliação da evolução clínica do paciente (DE NARDI et al., 2016).

O paciente apresenta clinicamente dor intensa, inflamação local, edema, endurecimento e espessamento da região, que pode acometer as mamas uni ou bilateralmente (DE NARDI et al., 2016). Pela avaliação histológica, percebe-se diversos êmbolos tumorais dos vasos linfáticos da derme nestes casos, motivo pelo qual o edema local e dos membros ipsilaterais são comuns nos casos de carcinoma mamário inflamatório (DE NARDI et al., 2016). 
É importante ressaltar, que no momento da avaliação física do paciente com tumor de mama, que todas as mamas sejam palpadas de maneira criteriosa, principalmente porque tumores com menos de $0,5 \mathrm{~cm}$ são de difícil detecção e palpação, principalmente nas mamas abdominais caudais e inguinal, que apresentam evoluído tecido mamário (DE NARDI et al., 2016).

\section{Diagnóstico e estadiamento}

Cassali et al. (2014) fizeram um importante trabalho formando um consenso para diagnóstico, prognóstico e tratamento dos tumores mamários caninos, considerando a importância clínica e epidemiológica da enfermidade, uma vez que trazem que os tumores mamários são o processo neoplásico mais comum em cadelas.

O inicio do tratamento do câncer começa com o diagnóstico. O profissional veterinário, em consulta de rotina ou até mesmo quando o proprietário traz o paciente com a queixa da neoformação nodular, deve colher informações importantes à respeito do histórico médico do paciente, seu ciclo reprodutivo, englobando regularidade de cios, número de cios ou gestações, histórico de uso de terapia hormonal (geralmente com intuito anticoncepcional), histórico de abortos, etc. Durante a avaliação clínica ainda, o clínico deve ainda correlacionar o início do aparecimento das lesões com a apresentação clínica atual, bem como, o histórico de neoplasias anteriores (CASSALI et al., 2014). É de extrema necessidade que o médico veterinário avalie ainda a possibilidade de lesões iniciais em outras glândulas.

É de consenso com a maior parte da literatura, que o estadiamento tumoral seja realizado em qualquer paciente com suspeita de câncer. Não se trata de maneira diferente os tumores mamários em cadelas e gatas.

O estadiamento clínico é determinado através do sistema TNM estabelecido pela Organização mundial da Saúde (OMS) para tumores mamários caninos. Neste sistema, T está relacionado com o tamanho da lesão primária, $\mathrm{N}$ com 0 acometimento de linfonodos regionais, e $M$ trata da presença ou ausência de metástases à distância detectáveis (CASSALI et al., 2014). As avaliações deste sistema, podem ser vistas conforme os quadros 1 e 2 abaixo. Alguns autores podem ainda, sugerir o estadiamento TNM em dois momentos, sendo o TNMc, aquele que se realiza durante a consulta, e o TNMp após a realização de exames complementares.

QUADRO 1 - Classificação adaptada do TNM dos tumores de mama em cadelas

\begin{tabular}{|l|l|}
\hline Tumor (T) & $\begin{array}{l}\text { T0 Sem evidência de tumor primário } \\
\text { T1 Tumor }<3 \mathrm{~cm} \\
\text { T2 Tumor entre } 3 \text { e } 5 \mathrm{~cm} \\
\text { T3 Tumor }>5 \mathrm{~cm}\end{array}$ \\
\hline Linfonodos regionais $(\mathrm{N})$ & $\begin{array}{l}\text { N0 Sem metástase linfonodal inguinal ou axilar } \\
\text { N1 Linfonodo metastático }\end{array}$ \\
\hline
\end{tabular}




\begin{tabular}{|l|l|}
\hline Metástases (M) & $\begin{array}{l}\text { M0 Sem metástase à distância } \\
\text { M1 Metástase à distância, incluindo linfonodos } \\
\text { distantes }\end{array}$ \\
\hline
\end{tabular}

Fonte: Cassali et al. (2017).

As diferentes combinações dos critérios acima dão base para o estadiamento clínico que varia conforme o quadro 2.

QUADRO 2 - Estadiamento clínico de tumores em cadelas

\begin{tabular}{|l|l|l|l|}
\hline Estadiamento & $\mathbf{T}$ & $\mathbf{N}$ & $\mathbf{M}$ \\
\hline Estágio I & $\mathrm{T} 1$ & $\mathrm{~N} 0$ & $\mathrm{M} 0$ \\
\hline Estágio II & $\mathrm{T} 2$ & $\mathrm{~N} 0$ & $\mathrm{M} 0$ \\
\hline Estágio III & $\mathrm{T} 3$ & $\mathrm{~N} 0$ & $\mathrm{M} 0$ \\
\hline Estágio IV & Qualquer T & $\mathrm{N} 1$ & $\mathrm{M} 0$ \\
\hline Estágio V & Qualquer T & Qualquer N & $\mathrm{M} 1$ \\
\hline
\end{tabular}

Fonte: Cassali et al. (2017).

\section{Radiografia}

Dentre estes exames complementares, podemos citar as radiografias torácicas. Considerando que os pulmões são o sítio mais comum de metástases à distância para a maioria dos tumores mamários malignos, a realização da radiografia é de caráter quase obrigatório (CASSALI et al., 2014). Metástases torácicas ocorrem em $25 \%$ a $50 \%$ dos cães com neoplasias mamárias malignas no momento do diagnóstico (MACPHAIL, 2007). Radiografias abdominais devem ser realizadas para avaliação de tamanho dos linfonodos ilíacos para os casos em que os tumores se localizam nas glândulas mais caudais (MACPHAIL, 2007).

Devem ser realizadas por técnico habilitado em três incidências: lateral direita, lateral esquerda e ventrodorsal. Esta técnica, como todas, apresenta certas limitações, como por exemplo o fato de que é apenas capaz de detectar lesões com 6 a $8 \mathrm{~mm}$ de diâmetro (CASSALI et al., 2014). Lesões menores podem ser detectadas através da tomografia computadorizada (CASSALI et al., 2014).

\section{Ultrassonografia}

A ultrassonografia abdominal pode ser realizada com o intuito de observar metástases à distância, mas não deve ser selecionada em detrimento da radiografia torácica. Ultrassonografias abdominais normalmente detectam metástases abdominais (MACPHAIL, 2007).

Alguns tumores mamários podem fazer metástases em outros órgãos parenquimatosos, como baço e fígado, em sequencia, ou não, das lesões metastáticas nos pulmões. A observação de metástases à distância, eleva o estágio do câncer na classificação de acordo com o sistema, TNM e consequentemente está associada à um prognóstico desfavorável (CASSALI et al., 2014). 


\section{Citologia}

O uso da citologia aspirativa aumentou com o tempo, e o aumento do nível de concordância com os resultados histopatológicos de uma mesma amostra tem sido cada vez mais descrito (CASSALI et al., 2014). A técnica pode ser utilizada no diagnóstico do tumor primário sem interferir no planejamento cirúrgico, porém é mais utilizada para detecção de metástases nos linfonodos regionais (CASSALI et al., 2014). A citologia deve ser realizada em linfonodos que contenham alterações em seu volume, formato e/ou consistência durante a avaliação clínica (CASSALI et al., 2014).

\section{Histopatologia}

O exame histopatológico ainda é considerado o exame confirmatório da neoplasia mamária, sendo, portanto, o exame para diagnóstico definitivo dos tumores mamários (DE NARDI et al., 2016). A biópsia excisional é o método diagnóstico recomendado para tumores mamários caninos (CASSALI et al., 2014). Este método diagnóstico pode ser inclusive considerado curativo para cães com tumores pequenos e bem diferenciados.

O exame histopatológico permite a avaliação do tipo tumoral além de outras informações mais específicas como é obtido através da avaliação histopatológica, na qual se verifica o tipo histológico, o pleomorfismo nuclear, o grau de malignidade, (graus de diferenciação), índice mitótico, presença ou ausência de necrose, arquitetura tumoral, infiltração dos tecidos e vasos adjacentes, além da avaliação das margens (CASSALI et al., 2014; DE NARDI et al., 2016).

\section{Tratamento cirúrgico}

A cirurgia é a primeira linha de tratamento para os tumores mamários sendo considerada a terapia mais efetiva para o controle da doença localizada, com exceção do carcinoma inflamatório, no qual o tratamento cirúrgico não é aconselhado (CASSALI et al., 2014). Caldas et al. (2017) concordam que a extirpação do tumor com margem cirúrgica, ainda é a melhor maneira de alcançar a cura.

A remoção cirúrgica da neoplasia ainda é a técnica considerada ouro para o tratamento do tumor mamário em cães, e é o método que apresenta melhor controle local doença, com exceção apenas dos casos de carcinoma inflamatório, como ressaltado anteriormente (PAPAZOGLOU et al., 2014). Uma vez que o tipo de seleção de técnica aparentemente não tem efeito comprovado sobre a longevidade pós-cirúrgica do paciente, preconiza-se a abordagem mais simples para o tratamento (PAPAZOGLOU et al., 2014). A seleção da técnica a ser utilizada deve sempre ser feita de maneira individualizada para cada paciente e baseada no tamanho, aderência e fixação aos tecidos adjacentes, drenagem linfática, número total de lesões e probabilidade de atingir controle local da doença, porém deve-se sempre considerar que o principal objetivo da cirurgia oncológica mamária canina é a extirpação completa das massas tumorais com margens livres de tecido neoplásico através da técnica mais simples, considerando a possível extensão da neoplasia pelo sistema linfático local (PAPAZOGLOU et al., 2014). As opções de abordagens cirúrgicas aceitas hoje são: lumpectomia (ou nodulectomia), mastectomia, mastectomia regional, mastectomia unilateral ou bilateral (PAPAZOGLOU et al., 2014) (Figura 1). 
Daleck e de Nardi (2016) parecem ter a mesma opinião ao afirmar que a remoção em bloco é um método vantajoso ao paciente, e que a maior remoção de tecido mamário pode diminuir as chances de recidivas.

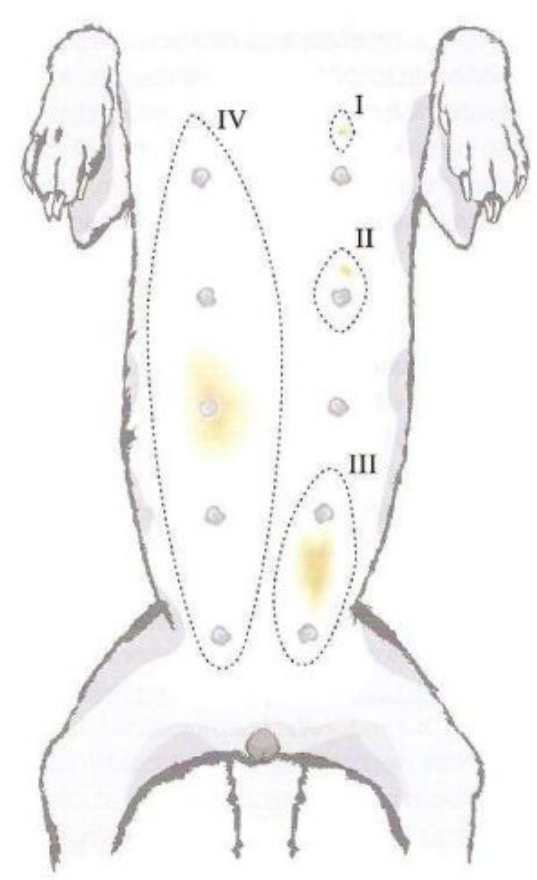

FIGURA 1. Técnicas de ressecção cirúrgica dos tumores mamários: (I) Lumpectomia; (II) Mastectomia simples; (III) Mastectomia regional; (IV) Mastectomia unilateral.

FONTE: Cassali et al. (2017).

\section{Drenagem linfática}

O sistema linfático é a principal via para geração de metástases de tumores mamários malignos em cães, portanto, o conhecimento do clínico e do cirurgião com relação à drenagem linfática mamária para que haja excisão cirúrgica adequada é indispensável (CASSALI et al., 2014). Por outro lado, sabe-se que a drenagem linfática das mamas se altera durante a evolução do câncer. Há relatos de conexões linfáticas entre mamas neoplásicas e normais, mas são raras (CASSALI et al., 2014).

A apresentação anatômica mais comum das mamas em uma cadela é possuir dois pares de cinco mamas, totalizando duas cadeias mamárias com cinco mamas cada (MACPHAIL, 2007). As mamas são designadas conforme sua localização; assim seguindo craniocaudalmente temos: um par de mamas torácicas craniais (M1/T1), um par de mamas torácicas caudais (M2/T2), um par de mamas abdominais craniais (M3/A1), um par de mamas abdominais caudais (M4/A2) e um par de mamas inguinais (M5/l). O tecido glandular tende a aumentar neste mesmo sentido, assim sendo, as glândulas inguinais são as que apresentam maior tecido mamário, e as torácicas craniais menos. Como consequência prática, temos o maior envolvimento neoplásico nesses tecidos mais abundantes (FEITOSA, 2016; CASSALI et al., 2017). A anatomia mamária da 
cadela pode ser vista pelo desenho esquemático (Figura 2) abaixo, que demonstra juntamente sua circulação venosa, arterial e linfática.

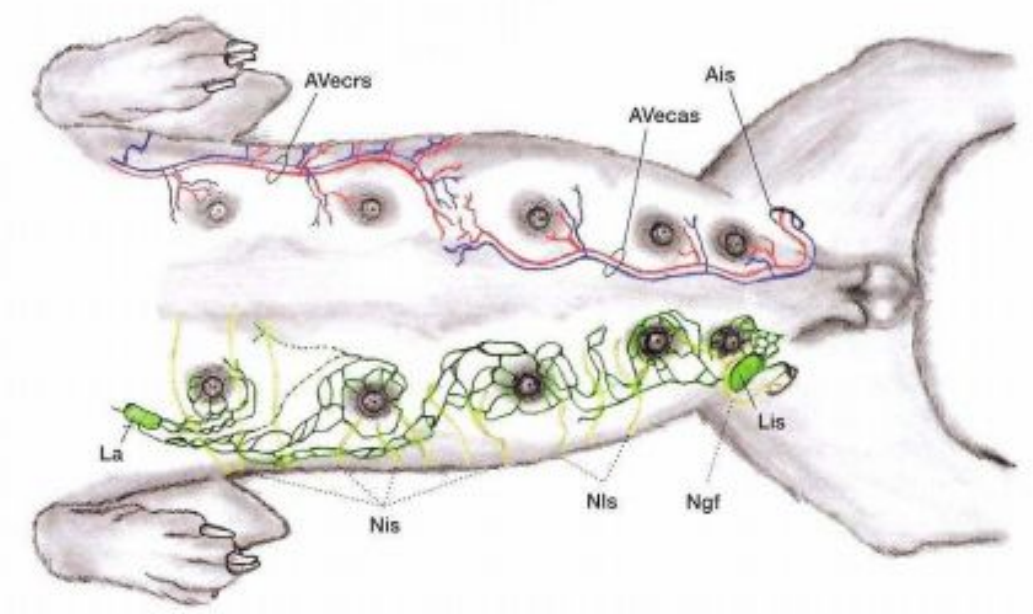

FIGURA 2. Desenho esquemático da circulação sanguínea (venosa - azul, arterial vermelha e linfática - verde) das mamas caninas.

FONTE: Cassali et al. (2017).

Mamas torácicas craniais e caudais drenam para os linfonodos axilares ipsilaterais (CASSALI et al., 2014). A mama abdominal cranial drena principalmente para o linfonodo axilar, mas drena simultaneamente para o inguinal, ambos ipsilaterais (CASSALI et al., 2014). As mamas abdominais caudais e inguinais drenam para o linfonodo inguinal superficial ipsilateral (CASSALI et al., 2014).

A extensão da cirurgia depende do estadiamento do paciente, da drenagem linfática das glândulas acometidas e do tamanho e localização da lesão (CASSALI et al., 2014; PAPAZOGLOU et al., 2014; CALDAS et al., 2017).

\section{Técnicas de mastectomia}

O paciente deve ser posicionado em decúbito dorsal com os membros torácicos extendidos e fixados cranialmente, bem como os pélvicos extendidos e fixados caudalmente, todos em uma posição relaxada (MACPHAIL, 2007). Todo o abdome ventral do paciente, bem como seu tórax caudal e áreas inguinais devem ser preparadas assepticamente e campos estéreis devem ser presos (MACPHAIL, 2007).

Uma incisão elíptica deve ser realizada ao redor da(s) mama(s) a ser(em) retirada(s), com margens de pelo menos 1 a $2 \mathrm{~cm}$ de tecido saudável em pele e profundamente em subcutâneo até a fáscia abdominal ou torácica externas (MACPHAIL, 2007; PAPAZOGLOU et al., 2014). Caldas et al. (2017) preferem margens mínimas de $3 \mathrm{~cm}$ para menor risco de comprometimento de tecido afetado. Este é um fator importante já que o tratamento efetivo do câncer em estágios iniciais com intuito de cura depende da mastectomia com margens livres (DIAS et al., 2016). Deve-se evitar incisar tecido mamário sempre que possível, porém em alguns momentos isso não é possível, uma vez que o tecido mamário pode ser confluente entre as diversas mamas adjacentes de uma mesma cadeia, por outro lado, a delimitação da linha entre as cadeias contralaterais é bem definida (MACPHAIL, 2007). Hemorragias superficiais devem ser controladas com eletrocoagulação, pinças hemostáticas ou através de ligaduras 
(MACPHAIL, 2007). E excisão em bloco pode ser realizada através da elevação de um dos bordos da incisão, e dissecação cuidadosa entre subcutâneo e fáscia adjacente (peitoral ou do reto abdominal) utilizando uma tesoura e tracionando o segmento de pele elevado para facilitar a dissecação (MACPHAIL, 2007).

Resseccionar a gordura e linfonodo inguinais, juntamente com a glândula mamária inguinal (MACPHAIL, 2007). Vale lembrar, que a ressecção em bloco das mamas torácicas não envolve a retirada do linfonodo auxiliar (MACPHAIL, 2007). Em caso de invasão subcutânea do tumor, excisar conjuntamente a fáscia muscular adjacente, e em alguns casos, quando o tumor envolver também a musculatura, a excisão deve incluir parte da parede abdominal (MACPHAlL, 2007). Seguir com a dissecação romba até que os vasos principais (principalmente epigástrica superficial cranial e epigástrica superficial caudal) sejam encontrados, e na sequência, ligá-los (MACPHAIL, 2007).

A epigástrica superficial cranial deve ser ligada bem próxima ao reto abdominal, entre as mamas torácica caudal e abdominal cranial, e da mesma maneira, ligar proximalmente a epigástrica superficial caudal próximo ao anel inguinal (MACPHAIL, 2007). Caldas et al. (2017) fizeram seu trabalho sugerindo a utilização de fios absorvíveis como categute cromado 2-0 ou poliglactina $9102-0$. Os ramos responsáveis pela irrigação das mamas torácicas, também devem ser ligados onde infiltram-se pela musculatura peitoral (MACPHAIL, 2007).Em seguida, a ferida deve ser lavada, e o tecido remanescente deve ser avaliado quanto às alterações morfológicas (FOSSUM, 2007; PAPAZOGLOU et al., 2014).

A síntese de uma mastectomia pode ser o momento mais desafiador da cirurgia, sendo que a obliteração do espaço morto e o manejo da tensão na linha de incisão são os principais problemas a serem enfrentados (PAPAZOGLOU et al., 2014). A aposição da pele, torna-se muito mais difícil na síntese da região torácica, pois a pele é muito menos flexível, e as costelas não permitem aplicar a mesma compressão que se aplica no abdome (MACPHAIL, 2007). Nestes casos, flaps de pregas axilares ou inguinais podem ser utilizados para diminuir a tensão nos bordos da sutura (MACPHAIL, 2007, PAPAZOGLOU et al., 2014). Para isto, utilizar fios monofilamentares absorvíveis ou inabsorvíveis para realizar a síntese da pele, utilizando padrões aposicionais ou grampos (MACPHAlL, 2007). Papazoglou et al. (2014) sugerem a utilização de suturas de alívio ao longo da incisão e na sequência, a utilização de suturas simples ou grampos, para o término da síntese entre as suturas pré posicionadas.

MacPhail (2007), sugere liberar a pele ao redor da ferida do tecido subcutâneo para avançar ao centro da ferida utilizando padrões de walking suture. Caso haja grande presença de espaço morto, drenos (Penrose, por exemplo) devem ser colocados para evitar o acúmulo de fluidos (MACPHAlL, 2007). Papazoglou et al. (2014) sugerem a utilização de drenos ativos, já Caldas et al. (2017) sugerem o emprego do dreno cirúrgico nas mastectomias regionais, principalmente envolvendo as mamas abdomino-inguinais. Também, deve-se promover a aposição das bordas da pele, suturando o subcutâneo ou utilizando um padrão subcuticular (MACPHAIL, 2007) contínuo ou interrompido, utilizando fios monofilamentares absorvíveis 3-0 ou 4-0 como a polidioxanona, poliglecaprone ou poligliconato (MACPHAIL, 2007). Papazoglou et al. (2014), por outro lado, trazem estudo que o tempo cirúrgico dos pacientes nos quais a aproximação subcutânea não é feita, é consideravelmente menor do que nos casos em que a pele é suturada diretamente, e que não há maior formação de seroma ou maior tempo de 
hospitalização pós-operatória destes pacientes. Já com relação à utilização de drenos, os mesmos autores concluem que nos casos em que há aplicação da correta técnica e utilização dos princípios de Halsted, o uso do dreno é dispensável (PAPAZOGLOU et al., 2014).

Por fim, de acordo com MacPhail (2007), deve-se utilizar bandagens compressivas e largas ao redor da circunferência torácica e/ou abdominal para promover compressão de espaço morto, mobilização tecidual e dar suporte à ferida (MACPHAIL, 2007). Caldas et al. (2017), também relatam que o curativo local compressivo preveniu a formação de seromas e permitiu uma evolução cicatricial favorável. Outra função importante da bandagem, seria a proteção dos drenos (PAPAZOGLOU et al., 2014).

As complicações pós-operatórias normalmente incluem: formação de seroma, infecção de ferida, deiscência de pontos, necrose isquêmica, auto-mutilação, hemorragias, edema de membros e recorrência tumoral (PAPAZOGLOU et al., 2014). Estudos em humanos trazem como principais complicações a longo prazo de pacientes submetidas ao tratamento cirúrgico do câncer de mama, angústia psicosocial, linfedema, privação estrogênica, insônia, fadiga e deficiências cogntivas (HENNEGHAN; HARRISON, 2014).

\section{Lumpectomia (nodulectomia)}

A lumpectomia deve ser considerada para retirada de únicos tumores superficiais, sólidos, e não aderidos com menos do que $0,5 \mathrm{~cm}$ (CASSALI et al., 2014). Lesões maiores implicam na necessidade de remoção da glândula inteira. Já Papazoglou et al. (2014) consideram que a técnica que pode ser aplicada à nódulos benignos, menores do que 0,5 a $1 \mathrm{~cm}$ de diâmetro, firmes e não aderidos ou fixados à pele ou outros tecidos adjacentes. Os autores justificam que a lumpectomia de massas malignas geralmente evolui para recorrência, e deve, portanto, ser evitada nestes casos (PAPAZOGLOU et al., 2014). Nestes casos, a incisão elíptica deve ser extendida por pelo menos $2 \mathrm{~cm}$ em todos os sentidos e profundidade (PAPAZOGLOU et al., 2014).

A técnica consiste na incisão da pele ao redor do nódulo, que por sua vez é dissecado de forma romba do parênquima ao seu redor, com a utilização de pinças hemostáticas de Halsted ou tesouras (PAPAZOGLOU et al., 2014). Biópsias incisionais também podem ser feitas através da adoção desta mesma técnica (PAPAZOGLOU et al., 2014). Para síntese, deve-se realizar controle hemorrágico, e sutura da pele na sequência (PAPAZOGLOU et al., 2014).

\section{Mastectomia simples}

A mamectomia os mastectomia simples é indicada para lesões com mais de 3 $\mathrm{cm}$, que afetem apenas uma glândula, enquanto a mastectomia regional ou ressecção em bloco é indicada para remoção de múltiplas glândulas afetadas com tumores com mais de $3 \mathrm{~cm}$, que apresentem ligações linfáticas (CASSALI et al., 2014). A afecção da $A 1 \mathrm{com}$ tumores maiores do que $3 \mathrm{~cm}$, por consequência de seu potencial de drenagem linfático, indica mastectomia radical (CASSALI et al., 2014). Papazoglou et al. (2014) consideram que a remoção de apenas uma glândula mamária por inteiro, deve ser indicada para a retira de tumores maiores, centrais, que já apresentam alguma fixação à pele ou ao tecido subjacente (PAPAZOGLOU et al., 2014). 
Deve ser realizada através de uma incisão elíptica a $2 \mathrm{~cm}$ de cada bordo do tumor, ao redor da glândula mamária, e deve ser excisado em profundidade fáscia e musculatura concomitantemente, em caso de acometimento evidente (PAPAZOGLOU et al., 2014). Uma vez que o tecido mamário é bastante difuso, principalmente entre as glândulas, a remoção em bloco pode ser uma alternativa para não haver transecção de tecido glandular. Nestes casos, Papazoglou et al. (2014), indicam a retirada das mamas M1, M2 e M3 em bloco, ou das mamas M4 e M5, dependendo de qual mama estiver envolvida com o tumor.

\section{Mastectomia regional}

A mastectomia regional é indicada nos casos em que múltiplas mamas estarem afetadas por diversos tumores, ou quando o tumor está localizado entre mamas adjacentes (PAPAZOGLOU et al., 2014). Para tumores maiores do que 1 $\mathrm{cm}$, em mamas avulsas, pode-se utilizar a mastectomia regional considerando a ligação linfática das mamas, retirando em blocos T1, T2, e A1 conjuntamente, ou A2 e I, se for o caso.

A seleção das mamas a serem submetidas à mastectomia regional deve basear-se na drenagem linfática e venosa das glândulas afetadas, e a excisão deve conter, inclusive, o linfonodo de drenagem ipsilateral (PAPAZOGLOU et al., 2014). Portanto, considerando a possibilidade de drenagem ambígua de M3 para linfonodo axilar e inguinal, opta-se por realizar a mastectomia regional de M1, M2 e M3, ou M3, M4 e M5, quando for o caso (PAPAZOGLOU et al., 2014). Caldas et al. (2017), também são defensores da técnica de mastectomia regional, e a denomina quadranctectomia, propondo diferentes remoções em bloco considerando também a drenagem linfática, porém reconhecendo que suas considerações diferem da literatura convencional. Vê-se isso, quando os autores consideram que a retirada em bloco de A1, deva ser feita concomitantemente com A2 e I. Os autores neste mesmo estudo, relatam que as diferentes formas da técnica de quadrantectomia são de rápida e fácil execução, e que apresentam o benefício de o tempo cirúrgico ser curto, sendo estimado em 15 a 75 minutos. As abordagens das diferentes técnicas de quadrantectomia podem ser vistas conforme a Figura 3.

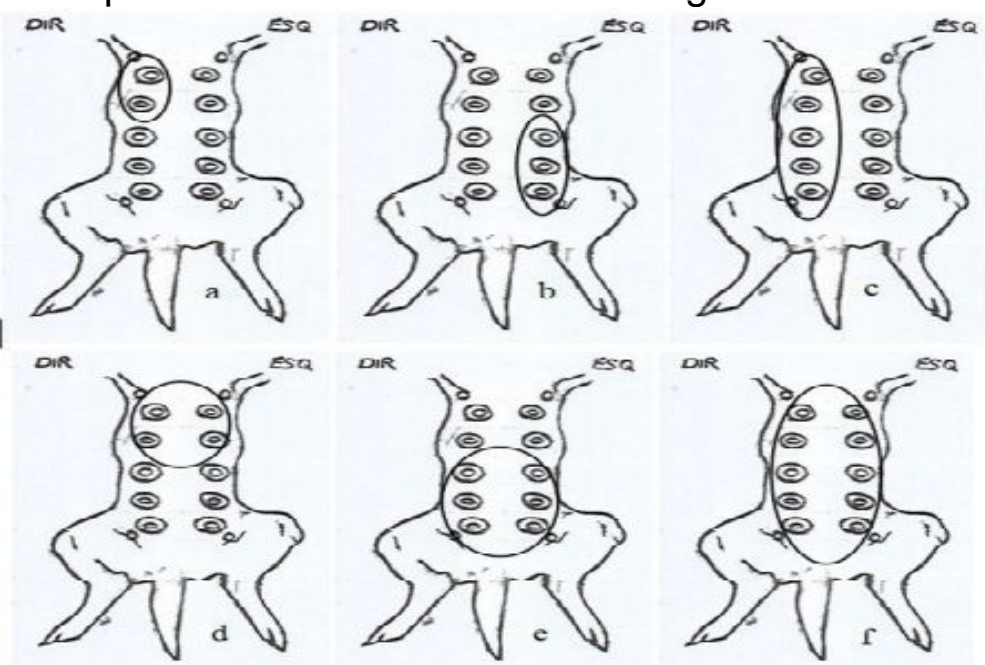

FIGURA 3. Técnicas de mastectomia e quadrantectomia de acordo com Caldas et al. (2017): (a) Quadrantectomia regional torácica; (b) Quadrantectomia regional abdomino-inguinal; (c) Mastectomia unilateral; (d) Quadrantectomia cranial total; (e) Quadrantectomia caudal total; (f) Mastectomia bilateral.

FONTE: Caldas et al. (2017). 
A linfadenectomia tem caráter diagnóstico, uma vez que o linfonodo se apresentar positivo pode interferir no prognóstico dos carcinomas mamários (PAPAZOGLOU et al., 2014). Atualmente, a detecção do linfonodo sentinela através de linfografia contrastada, pode ser uma maneira de auxiliar no planejamento cirúrgico, e promover a ressecção do linfonodo juntamente com toda a sua via linfática (PAPAZOGLOU et al., 2014). Esta técnica traz maiores benefícios, inclusive para aqueles linfonodos que não apresentam alterações de tamanho e consistência, e que são comumente de difícil acesso, como é o caso do linfonodo axilar (PAPAZOGLOU et al., 2014). Por outro lado, estudos em humanos demonstraram que pacientes com carcinoma mamário microinvasico (com menos de $1 \mathrm{~mm}$ de diâmetro) apresentam pequena incidência de metástases em linfonodos axilares, sendo a afecção linfonodal mais comum em pacientes jovens e com HER-2 (biomarcador prognóstico, será discutido mais adiante) positivos (HOLMRASMUSSEN et al., 2019).

\section{Mastectomia unilateral e bilateral}

A mastectomia unilateral envolve a retirada das mamas de M1 a M5 de mesma cadeia, como uma mesma unidade (PAPAZOGLOU et al., 2014). É indicado para casos em que há acometimento de múltiplas glândulas de diferentes regiões (PAPAZOGLOU et al., 2014). É mais rápida e simples de ser realizada do que múltiplas mastectomias simples (PAPAZOGLOU et al., 2014).

A mastectomia bilateral é indicada quando o acometimento de mamas diversas acontece em ambas cadeias, e pode ser executada em um ou dois tempos cirúrgicos (PAPAZOGLOU et al., 2014). Pacientes que apresentam pele pendular e tórax pouco profundo podem apresentar indicação de realização do procedimento bilateral em apenas uma das etapas cirúrgicas (PAPAZOGLOU et al., 2014). Pacientes que apresentam tórax profundo devem ser submetidos a dois procedimentos de mastectomia unilateral, um em cada cadeia, com intervalo de 6 a 8 semanas entre eles (PAPAZOGLOU et al., 2014).

Segundo Papazoglou et al. (2014), alguns cirurgiões podem preferir realizar procedimentos de mastectomia unilateral de forma profilática em pacientes jovens, que apresentem lesões benignas. Porém, o mesmo autor revela que procedimentos invasivos e extensos, principalmente mastectomias bilaterais, não são justificáveis por tratar-se de procedimentos bastante extensos e agressivos, sem estudos comprovando o aumento da longevidade dos pacientes.

A sugestão mais palpável e realista seria o acompanhamento regular destes pacientes predispostos, para detecção e intervenção de lesões iniciais. Um estudo de Stratmann et al. (2008), avaliou 99 cadelas que apresentavam tumor mamário único em apenas uma cadeia e que foram submetidas à mastectomia regional por um ano. Os autores concluíram que $58 \%$ dos pacientes voltaram a apresentar um tumor mamário em alguma mama de cadeia ipsilateral. Por outro lado, uma das limitações do estudo residiu no fato de que $42 \%$ das cadelas que apresentaram recorrência eram cadelas intactas, ou seja, não ovariohisterictomizadas, o que pode ter interferido no desenvolvimento da recorrência (STRATMANN et al., 2008). Assim sendo, Papazoglou et al. (2014) concluíram que a abordagem unilateral total pode ser um método eficaz e menos traumático para tratamento e prevenção da recorrência de tumores mamários, mas ainda propõem um esquema para auxiliar na seleção da técnica a ser aplicada a cada caso, conforme pode-se observar no quadro 3. 
QUADRO 3 - Guia para seleção do tipo de excisão cirúrgica para tumores mamários caninos, considerando sua extensão e localização.

\begin{tabular}{|c|c|}
\hline Localização tumoral & Tipo de excisão cirúrgica \\
\hline Tumor benigno único $<0,5-1 \mathrm{~cm}$ & Lumpectomia (nodulectomia) \\
\hline $\begin{array}{l}\text { Tumores benignos múltiplos ou tumores } \\
\text { malignos }<0,5-1 \mathrm{~cm} \text { em uma ou ambas } \\
\text { cadeias mamárias }\end{array}$ & $\begin{array}{l}\text { Mastectomia unilateral/regional } \\
\text { mastectomia bilateral }\end{array}$ \\
\hline $\begin{array}{l}\text { Grandes tumores múltiplos em uma ou } \\
\text { ambas cadeias }\end{array}$ & $\begin{array}{l}\text { Mastectomia unilateral/regional } \\
\text { mastectomia bilateral }\end{array}$ \\
\hline $\begin{array}{l}\text { Grande tumor único em apenas uma } \\
\text { glândula }\end{array}$ & Mastectomia unilateral ou regional \\
\hline $\begin{array}{l}\text { Grande tumor único e central em uma } \\
\text { glândula com limites anatômicos bem } \\
\text { definidos }\end{array}$ & $\begin{array}{l}\text { Mastectomia simples ou regional ou } \\
\text { mastectomia unilateral }\end{array}$ \\
\hline $\begin{array}{l}\text { Tumores malignos aderidos à tecido } \\
\text { adjacente }\end{array}$ & $\begin{array}{l}\text { Mastectomia unilateral/regional com } \\
\text { incorporação de musculatura e/ou fáscia }\end{array}$ \\
\hline $\begin{array}{l}\text { Tumor único ou múltiplo em glândulas } \\
\text { adjacentes ou entre glândulas }\end{array}$ & Mastectomia unilateral/regional \\
\hline $\begin{array}{l}\text { Tumores localizados ou entre as } \\
\text { glândulas } 1,2 \mathrm{e} 3\end{array}$ & $\begin{array}{l}\text { Mastectomia regional das glândulas } 1 \text { a } 3 \\
+ \text { retirada do linfonodo axilar ou } \\
\text { mastectomia unilateral }\end{array}$ \\
\hline $\begin{array}{l}\text { Tumores localizados ou entre as } \\
\text { glândulas } 3,4 \text { e } 5\end{array}$ & $\begin{array}{l}\text { Mastectomia regional das glândulas } 3 \text { a } 5 \\
+ \text { retirada do linfonodo inguinal ou } \\
\text { mastectomia unilateral }\end{array}$ \\
\hline
\end{tabular}

FONTE: Papazoglou et al., 2014.

De Nardi et al., (2002) realizaram um estudo retrospectivo com 333 cães acometidos com neoplasias de maneira geral, sendo que $45,64 \%$ destes pacientes eram fêmeas que apresentavam tumores em mamas. Este mesmo estudo, afirmou que a cirurgia foi a modalidade terapêutica mais utilizada, mas não foi específico ao detalhar a técnica utilizada. Relata também que em 11 destas fêmeas sem metástases ao diagnóstico, após a exérese mamária, instituiu-se a quimioprofilaxia para erradicar micrometástases, e que destas, 8 pacientes obtiveram sobrevida, em média de 18 meses. Esta informação de De Nardi nos indica que, apesar de preconizada a extirpação cirúrgica dos tumores mamários, mesmo que com quimioprofilaxia pós cirúrgica, a obtenção da cura acontece em apenas $72,8 \%$ dos casos.

\section{Prognóstico}

A clara determinação do prognóstico do paciente permite a seleção da terapia de forma individualizada. Este tipo de abordagem é importante para o sucesso do tratamento, e inclusive para a manutenção da qualidade de vida das pacientes que atingem a cura. Tal condição, já é uma preocupação para a medicina humana, já que a evolução na prevenção e tratamento dos pacientes com câncer de mama tem aumentado a longevidade destes (HENNEGHAN; HARRISON, 2014).

A primeira geração dos fatores prognósticos são os fatores clássicos como o estadiamento pelo Índice Prognóstico de Nottingham, o TNM.

Sabe-se que há variabilidade do comportamento biológico de 
lesões do mesmo tipo dentro do mesmo estágio, o que permitia que deduções prognósticas para carcinomas, por exemplo, variassem de alguns meses a algumas décadas (ZUCCARI, 2008). O Índice Prognóstico de Nottingham, portanto, que já foi considerado uma ferramenta poderosa para predizer prognósticos de carcinomas mamários em humanos é um exemplo disto (ZUCCARI, 2008).

O tamanho do tumor pode ser considerado um fator prognóstico independente para tumores mamários em cadelas, e deve ser considerado para a decisão relacionado à implantação ou não de terapia complementar (CASSALI et al., 2014). Tumores com até $3 \mathrm{~cm}$ de diâmetro são correlacionados significativamente com melhores prognósticos. Tumores com mais de $5 \mathrm{~cm}$ de diâmetro estão relacionados com maior malignidade, maior índice proliferativo e menor positividade para receptores de progesterona e, portanto, apresentam prognóstico reservado a sombrio (CASSALI et al., 2014).

Animais com metástases em linfonodos regionais exibem uma queda significativa na expectativa de vida comparada a indivíduos que testaram negativo para metástases em linfonodos (CASSALI et al., 2014). Em discordância, porém, Zuccari et al. (2008) trazem que nem a presença de metástases em linfonodos, seria um fator prognóstico dos tumores de mama canino.

A forma inflamatória do carcinoma mamário, também é determinante na avaliação prognóstica. Esta forma de câncer é bastante agressiva e caracteriza-se por um processo inflamatório na pele e mamas com a presença de êmbolos tumorais nos vasos linfáticos da derme (CASSALI et al., 2014). Considera-se que pacientes que apresentem esta apresentação clínica do tumor tenham prognóstico ruim.

A graduação histopatológica do tumor primário também pode servir para compor o prognóstico. Em medicina veterinária, o sistema de graduação para tumores mamários com critérios bem definidos não é frequentemente usado pelos patologistas. Dentre os mais populares temos, o de Misdorp e Gilbertson que se baseiam na combinação de características nucleares e celulares das células neoplásicas, sendo que o modelo proposto por Nottingham tem ganhado espaço entre os veterinários (CASSALI et al., 2014).

\section{Marcadores moleculares}

Os marcadores moleculares também têm sido utilizados para determinação de prognóstico e comportamento tumoral (CASSALI et al., 2014). Zuccari et al. (2008) nos traz que a utilização desses marcadores podem contribuir para um prognóstico tumoral mais criterioso, e dessa maneira seria possível deixar de lado as classificações complexas e inconclusivas. Esta visão moderna do câncer de mama em cadelas tem favorecido o tratamento e dessa maneira beneficiado proprietários e pacientes, uma vez que a seleção do tratamento passa a ser mais objetiva, individualizada e menos traumática e onerosa.

Em humanos, os fatores prognósticos mais utilizados para o carcinoma mamário são principalmente os linfonodos-negativos, além do tamanho do tumor, o grau histológico, o estadiamento e o "status" hormonal (ZUCCARI, 2008). Ainda a respeito da medicina humana, os principais marcadores biológicos aplicados e com melhores estudos a respeito de sua relação com o prognóstico da doença são os receptores de estrógeno, receptores de progesterona, expressão do gene p53 e cerb-B2 (HER-2), e o marcador de proliferação celular Ki-67 (ZUCCARI, 2008). Outros potenciais marcadores seriam 
marcadores de apoptose celular como a caspase-3, catepsina D, E-caderina e o fator de proliferação celular PCNA (ZUCCARI, 2008).

Como tratam-se de exames relativamente onerosos, em medicina veterinária tem-se preconizado a análise dos receptores hormonais e as expressões de COX-2 e Ki-67, principalmente porque podem indicar um protocolo terapêutico específico (CASSALI et al., 2014). Normalmente, tumores pouco diferenciados e potencialmente malignos apresentam expressão de COX-2 e Ki-67 aumentadas, e são inversamente relacionados com a expressão de receptores para progesterona (CASSALI et al., 2014).

E por último, temos ainda a detecção de marcadores tumorais séricos, que nada mais são do que produtos normais do metabolismo celular que aumentaram sua produção decorrente da transformação celular maligna (CASSALI et al., 2014). Em mulheres, os marcadores mais utilizados são o CA 15.3 (antígeno cancerígeno CA15.3) e o antígeno carcinoembionico (CEA) (CASSALI et al., 2014).

\section{Receptores de estrógeno e progesterona}

Assim como em humanos, tumores mamários em cadelas têm ganho diferentes classificações de acordo com estudos moleculares e prognósticos, nos quais fenótipos moleculares tornaram-se importantes para a definição de subtipos tumorais baseados na expressão de marcadores imuno-histoquímicos como os receptores de estrógeno e progesterona, entre outros (CASSALI et al., 2018).

O estrogênio atravessa as membranas celular e nuclear, e ao chegar no núcleo liga-se ao receptor de estrogênio formando um complexo que ativa sequencias específicas de genes que, por sua vez, controlam o crescimento e a diferenciação celular (ZUCCARI et al., 2008).

O tumor de mama, é resultante do processo carcinogênico compreendido por vários estágios: iniciação, promoção, dependência e autonomia (FONSECA; DALECK, 2000). Normalmente algum fator desencadeante, seja ele radiação, exposição química, etc., serve como agente iniciador do processo de carcinogênese, e os fatores endócrinos são responsáveis pela promoção do tumor (FONSECA; DALECK, 2000). Durante a fase de promoção, as células tumorais alvo diferem das normais por necessitarem do estímulo hormonal para sua sobrevivência, e não apenas para sua atividade secretória, portanto, acredita-se que se o aporte hormonal for removido neste momento, todas as células tumorais desapareceram (FONSECA; DALECK, 2000).

Fonseca e Daleck (2000) afirmam que os hormônios agem como promotores e não iniciadores no desenvolvimento da neoplasia mamária, e que quando existe esta relação normalmente os tumores são dependentes de altos níveis hormonais para multiplicação. Os mesmos autores denominam esta fase como fase de dependência do tumor. Acompanhando a evolução tumoral hormônio-dependente, aqueles autores relatam que depois desta fase de dependência, os tumores acabam eventualmente tornando-se autônomos, e neste momento já há perda de características de diferenciação celular da linhagem de origem, e a celularidade acaba tornando-se bem diferenciada.

De forma geral, nos tumores malignos, a expressão dos genes que codificam os receptores desses hormônios pode estar diminuída, em particular nas neoplasias de maior grau de malignidade ou nas fases mais avançadas da doença (FONSECA; DALECK, 2000). A presença de receptores para estrógeno (RE) no citoplasma de células tumorais é correlação direta da dependência 
hormonal dessas neoplasias, e a presença simultânea de $R E$ e receptores de progesterona (RP) reforça ainda mais essa dependência (FONSECA; DALECK, 2000).

O status destes receptores hormonais (RE e RP) deve ser considerado mais como um marcador preditivo da resposta ao tratamento hormonal do que como marcador prognóstico propriamente dito (ZUCCARI et al., 2008). Porém, é possível inferir que animais com tumores de mama contendo RE e RP, ou somente RE, apresentam prognóstico melhor do que aqueles que possuem somente RP, uma vez que normalmente estão associados a tumores bem diferenciados (FONSECA; DALECK, 2000). Zuccari et al. (2008) têm a mesma opinião, afirmando que o perfil em que o paciente apresenta expressão apenas de RP e em grande quantidade estão associados a raras respostas ao tratamento hormonal e com pior prognóstico.

\section{Outros biomarcadores}

O gene p53 foi durante muito tempo considerado um anti-oncogene que codificava a proteína P53, que é um regulador de transcrição, pois parece estar envolvido na regulação celular e indução do apoptose. Porém, se um indivíduo herda só uma cópia funcional do gene p53 de seus pais, tem maior predisposição ao câncer e usualmente desenvolve muitos tumores, independentes em diferentes órgãos durante a vida adulta (FONSECA; DALECK, 2000).

Normalmente, os genes supressores de tumor regulam o crescimento celular codificando proteínas que atuam na inibição da proliferação celular, e o gene p53 é um desses representantes (ZUCCARI et al., 2008). Entre outros efeitos, uma mutação no gene p53 permite a produção de uma proteína p53 defeituosa, que é eliminada de forma vagarosa nas células, permitindo sua detecção pela imunohistoquímica (ZUCCARI et al., 2008).

A expressão exacerbada desta proteína tem sido observada em diversos tipos tumorais, incluindo carcinomas mamários e está associada com a agressividade tumoral em humanos, principalmente em pacientes sem metástases em linfonodos, e em cadelas a expressão é maior em cadelas jovens apresentando neoplasias mamárias (ZUCCARI et al., 2005; ZUCCARI et al., 2008). Pacientes humanos que apresentam câncer de mama ainda jovens, normalmente apresentam prognóstico adverso, além de apresentarem doença mais avançada e agressiva (VILLARREAL-GARZA et al., 2017. Zuccari et al. (2008) afirmam que é possível inferir, portanto, que a expressão do mutante p53 está associada com taxa de proliferação tumoral alta, além de recorrência precoce da doença e menor sobrevida nas neoplasias mamárias linfonodo-negativas.

O proto-oncogene C-erb-B-2, ou oncogene HER-2/neu codifica uma proteína receptora de membrana semelhante ao receptor do fator de crescimento epidérmico (ZUCCARI et al., 2008). Sua expressão é associada a um aumento da atividade proliferativa das lesões e, especialmente nos grupos em que já há metástases em linfonodos, são indícios de prognóstico ruim (ZUCCARI et al., 2008). Além disso, estudos mostram que pacientes com expressão deste gene são menos beneficiadas pelo tratamento hormonal (ZUCCARI et al., 2008). Na espécie canina é associada à diagnóstico histopatológico de malignidade, mas não é relacionada com a presença de invasão local ou doença metastática regional (ZUCCARI et al., 2008).

O Ki-67 é um antígeno nuclear que está presente nas fases ativas do ciclo celular e ausente na fase de repouso (ZUCCARI et al., 2008). Considera-se que valores aumentados de Ki-67 tem correlação 
positiva com metástase, morte por neoplasia e baixa taxa de sobrevivência sem doença (ZUCCARI et al., 2008).

Zuccari et al. (2008) sugerem que a E-caderina seja um potente supressor de invasão nos tumores mamários, e a perda da sua expressão seja indício de prognóstico ruim. Por outro lado, os mesmos autores trazem que a alta expressão de E-caderina indica que a adesão entre as células é preservada e consequentemente, o risco de metástase à distância é consideravelmente baixo, uma vez que a possibilidade de células neoplásicas atingirem a corrente circulatória é quase nula.

As caspases são proteases que controlam o início do processo de apoptose celular. A correlação entre índice apoptótico e proliferação celular parece ser bastante positiva, principalmente em carcinomas mamários, indicando que a apoptose está diretamente relacionada à taxa de proliferação tumoral na tentativa de controlar seu crescimento (TERZIAN et al., 2007). Estudos vem propondo que a marcação da caspase-3 possa ser usada no controle da resposta aos tratamentos quimioterápicos, quanto a possível resistência de drogas (ZUCCARI et al., 2008). O alto número de células apoptóticas está relacionado a um prognóstico não favorável (TEZIAN et al., 2007).

\section{CONSIDERAÇÕES FINAIS}

O câncer de mama em cadelas é uma afecção comum na rotina de pequenos animais, e por este motivo deve ser diagnosticada e tratada de maneira eficiente. Para isso, o médico veterinário deve estar atualizado. A apresentação clínica do câncer se dá basicamente pela constatação da presença de nódulos em uma ou várias mamas, que podem medir de 0,5 a mais $5 \mathrm{~cm}$ de diâmetro. $O$ tamanho do tumor, quantidade, localização, afecção de linfonodos sentinelas, e presença de metástases à distância permitem o estadiamento tumoral no sistema TNM, que ainda é utilizado para a seleção da abordagem terapêutica. A histopatologia é o método de eleição para o diagnóstico do tipo tumoral, e consequentemente é fator determinante para criação do prognóstico junto ao proprietário. Exames complementares como citologia pré-cirurgia, ultrassonografia e radiografia torácica são necessárias para a seleção da abordagem terapêutica.

A cirurgia é o tratamento de eleição para pacientes com câncer de mama. A seleção da técnica deve basear-se no estadiamento tumoral (TNM), número e localização dos tumores e drenagem linfática das glândulas acometidas. Esta técnica isolada, por outro lado, não é absoluta para a criação do prognóstico da paciente. Várias técnicas de tratamento cirúrgico têm sido utilizadas, e são elas: lumpectomia, mastectomia simples, mastectomia regional, mastectomia unilateral e mastectomia bilateral. Alguns autores divergem quanto à drenagem linfática da mama abdominal cranial, o que promove divergência na extirpação das mamas quando utilizada a técnica de mastectomia regional. Estudos mostram que a incidência de recidivas é menor quando técnicas mais agressivas são utilizadas, como a mastectomia unilateral, mesmo para nódulos únicos, e que a mastectomia bilateral ainda é uma técnica muito radical para ser aplicada apenas como profilaxia.

Os marcadores biomolecures p53, Ki-67, E-caderina, receptores hormonais RE e RP, C-erb-B-2 e caspase-3 podem ser utilizados como fatores prognósticos e/ou preditivos para o câncer de mama em cadelas. 


\section{REFERÊNCIAS}

CASSALI, G. D.; CAMPOS, C. B.; BERTAGNOLLI, A. C.; ESTRELA-LIMA, A.; LAVALLE, G. E. et al. Consensus for the Diagnosis, Prognosis and Treatment of Feline Mammary Tumors. Brazilian Journal of Veterinary Research and Animal Science. v. 55, n. 2, p. 1-17. 2018. Disponível em https://doi.org/10.11606/issn.16784456.bjvras.2018.135084. doi: 10.11606/issn.1678-4456.bjvras.2018.135084

CASSALI, G. D.; LAVALLE, G. E.; FERREIRA, E.; ESTRELA-LIMA, A.; DE NARDI, A. B. et al. Consensus for the Diagnosis, Prognosis and Treatment of Canine Mammary Tumors. Brazilian Journal of Veterinary Pathology, v. 7, n. 2, p. 38-69, 2014. Disponível em <http://bjvp.org.br/bjvp-archive/2015/07/vol-7-n-2-july-2014/>. Acesso em: 24 fevereiro 2019.

CASSALI, G.D.; FERREIRA, E.; CAMPOS, C.B. Patologia mamária canina: do diagnóstico ao tratamento. 1. ed. São Paulo: Editora MedVet, 2017. 224p.

CALDAS, S. A.; OLIVEIRA, M. C.; OLIVEIRA, L. C., FREIRE, K. R. F.; CAMPOS, A. $C$. et al. Vantagens da técnica de quadrantectomia em cadelas com neoplasias mamárias. Brazilian Journal of Veterinary Medicine, v. 39, n. 3, p. 190-197. 2017. Disponível em <https://doi.org/10.29374/2527-2179.bjvm010517>. doi: 10.29374/2527-2179.bjvm010517

DE NARDI, A. B.; FERREIRA, T. M. R.; DA ASSUNÇÃO, K. A. In: Neoplasias mamárias. DALECK, C. R.; DE NARDI, A. B. Oncologia em cães e gatos 2. ed. Rio de Janeiro: Roca, 2016. p. 726-756.

DE NARDI, A. B.; RODASKI, S.; SOUSA, R.S.; COSTA, T.A.; MACEDO, T.R., et al. Prevalência de neoplasias e modalidades de tratamento em cães, atendidos no Hospital Veterinário da universidade Federal do Paraná. Archives of Veterinary Science, v. $7, \quad$ n. 2, p. 15-26. 2002. Disponível em <http://dx.doi.org/10.5380/avs.v7i2.3977>. doi: 10.5380/avs.v7i2.3977

DIAS, M. L. M.; ANDRADE, J. M. L.; CASTRO, M. B.; GALERA, P. D. Survival analysis of female dogs with mammary tumors after mastectomy: epidemiological, clinical and morphological aspects. Pesq. Vet. Bras. v. 36, n. 3, p. 181-186. 2016. Disponível em: <http://dx.doi.org/10.1590/S0100-736X2016000300006>. doi: $10.1590 / \mathrm{S} 0100-736 \times 2016000300006$

FEITOSA, F. L F. Semiologia da Glândula Mamária de éguas, cadelas e gatas. In: FEITOSA, F. L F. Semiologia Veterinária: a arte do diagnóstico. 4. ed. São Paulo, SP. Roca, 2016. p. 349 - 352.

FONSECA, C. S.; DALECK C. R. Neoplasias mamárias em cadelas: influência hormonal e efeitos da ovariohisterectomia como terapia adjuvante. Ciência Rural, Santa Maria, v. 30, n. 4, p. 731-736. 2000. Disponível em < http://dx.doi.org/10.1590/S0103-84782000000400030>. doi: 10.1590/S010384782000000400030 
MACPHAIL, C. M. Neoplasias mamárias. In: FOSSUM, T.W. Cirurgia de pequenos animais. $3^{\mathrm{a}}$ ed. Elsevier Editora, 2007. p. $809-814$

HENNEGHAN. A. M.; HARRISON, T. Complementary and Alternative Medicine Therapies as Symptom Management Strategies for the Late Effects of Breast Cancer Treatment. Journal of Holistic Nursing American Holistic Nurses Association. v. 33, n. 1, p. 84-97. $2015 . \quad$ Disponível em < https://doi.org/10.1177/0898010114539191>. doi: 10.1177/0898010114539191

HOLM-RASMUSSEN E.V, JENSEN, M. B.; BALSLEV, E.; KROMAN, N; TVEDSKOV, T. F. Sentinel and non-sentinel lymph node metastases in patients with microinvasive breast cancer: a nationwide study. Breast Cancer Res Treat. Ecancer. 2019. p. 1-7. Disponível em <https://doi.org/10.1007/s10549-019-052004>. doi: 10.1007/s10549-019-05200-4

PAPAZOGLOU, L. G., BASDANI, E.; RABIDI, S.; PATSIKAS, M. N.; KARAYIANNOPOULOU, M. Current surgical options for mammary tumor removal in dogs. Journal of Veterinary Science and Medicine. v. 2, n. 1, p. 1-6. 2014. Disponível em < http://www.avensonline.org/wp-content/uploads/JVSM-2325-464502-0007.pdf >. Acesso em: 24 fevereiro 2019.

PINTO, J. A.; PINILLOS, L.; VILLAREAL-GARZA, C.; MORANTE, Z.; VILLARÁN M. N., et. al. Barriers in Latin America for the management of locally advanced breast cancer. Ecancer. v. 13, n. 897, p 1-14. 2019. Disponível em <https://doi.org/10.3332/ecancer.2019.897>. doi: 10.3332/ecancer.2019.897

TERZIAN, A. C. B.; ZUCCARI, D. A. P. C.; PEREIRA, R. S., PAVAM, M. V.; RUIZ, C. $\mathrm{M}$. et al. Avaliação da caspase-3 e Ki-67 como marcadores prognósticos nas neoplasias mamárias em cadelas. Brazilian Journal of Veterinary Research and Animal Science. São Paulo, v. 44. n. 2, p. 96-102, 2007. Disponível em < https://www.revistas.usp.br/bjvras/article/view/26647/28430>. Acesso em: 30 fevereiro 2019.

STRASSER-WEIPPL, K.; CHAVARRI-GUERRA, Y.; VILLAREAL-GARZA， C.; BYCHKOVSKY, B. L.; DEBIASSE, M., et al. Progress and remaining challenges for cancer control in Latin America and the Caribbean. The Lancet Oncology Commission. v. 16 n. 14. p. 1405 - 1438. 2015. Disponível em < https://doi.org/10.1016/S1470-2045(15)00218-1>. doi: 10.1016/S14702045(15)00218-1

STRATMANN N.; FAILING, K.; RICHTER, A.; WEHREND, A. Mammary tumor recurrence in bitches after regional mastectomy. Vet Surg. v. 37. p. 82-86. 2008. Disponível em <doi.org/10.1111/j.1532-950X.2007.00351.x>. doi: 10.1111/j.1532950X.2007.00351

VILLARREAL-GARZA, C.; MOHAR, A.; BARGALLO-ROCHA, J. E.; LASAGONSEBATT, F.; REYNOSO-NOVERÓN, N., et al. Molecular subtypes and prognosis in young Mexican women with breast cancer. Clinical Breast Cancer, v. 
17, n. 3, p. 95-102. 2016. Disponível em < http://dx.doi.org/10.1016/j.clbc.2016.11.007>. doi: 10.1016/j.clbc.2016.11.007

ZUCCARI, D. A. P. C.; BERTON, C.R.; TERZIAN, A. C. B.; RUIZ, C. M. Fatores prognósticos e preditivos nas neoplasias mamárias - importância dos marcadores imuno-histoquímicos nas espécies humana e canina - estudo comparativo. Arquivos de Ciência da Saúde. v. 15 n. 4, p. 189-198. 2008. Disponível em $<$ http://repositorio-racs.famerp.br/racs_ol/vol-15-4/IDB\%20293.pdf >. Acesso em: 03 de março 2019

ZUCCARI, D. A. P. C., TERZIAN, A. C. B.; PEREIRA, R.S.; PAVAM, M. V., RUIZ, C. M.; et al. Avaliação imuno-histoquímica do gene p53 nas neoplasias mamárias caninas. ARS VETERINÁRIA. v. 21, n. 3, p. 344-350, 2005. Disponível em <http://dx.doi.org/10.15361/2175-0106.2005v21n3p344-350>. doi: 10.15361/21750106.2005v21n3p344-350 